\title{
Short Chain Chlorinated Paraffins in Mollusks from Coastal Waters in the Chinese Bohai Sea
}

\author{
Bo Yuan, Thanh Wang, Nali Zhu, Kegang Zhang, Lixi Zeng, Jianjie Fu, Yawei Wang,* and Guibin Jiang
}

State Key Laboratory of Environmental Chemistry and Ecotoxicology, Research Center for Eco-Environmental Sciences, Chinese Academy of Sciences, Beijing 100085, China

\section{Supporting Information}

ABSTRACT: As an extremely complex group of persistent organic pollutants (POPs) candidates in the Stockholm Convention, short chain chlorinated paraffins (SCCPs) have been of extensive concern in recent years. In this study, nine bivalve and two gastropod species were collected in 2009 to evaluate the spatial distributions and potential factors influencing the bioaccumulation of SCCPs in mollusks in the Chinese Bohai Sea. The concentrations of $\sum$ SCCPs in the mollusks were in the range 64.9$5510 \mathrm{ng} / \mathrm{g}$ (dry weight) with an average chlorine content of $61.1 \% . \mathrm{C}_{10}$ and $\mathrm{C}_{11}$ were the predominant homologue groups of SCCPs, which accounted for about $29.7 \%$ and $34.9 \%$ of $\sum$ SCCPs, respectively. Six and seven chlorinated substituents were the main congener groups. Mya arenaria (Mya), Mactra veneriformis (Mac), and Crassostrea talienwhanensis (Oyster, Ost) had higher average concentrations of SCCPs than other species, implying that these bivalves could be used as sentinels to indicate SCCPs contamination in this coastal region. A significant positive linear relationship was found between SCCP concentrations and lipid content of the mollusks, whereas the lipidnormalized SCCP concentrations were negatively linear-related to the trophic levels (TL), which implied that SCCPs did not show biomagnification in mollusks in this region.

\section{INTRODUCTION}

Chlorinated paraffins (CPs) belong to a class of chlorinated derivatives of $n$-alkanes containing 10-30 carbon atoms and are extensively used in metal-working fluids, paints, sealants, leather treatment chemicals, flame retardants, plasticizers in rubbers, and polymers such as polyvinylchloride (PVC). ${ }^{1} \mathrm{CPs}$ are classified according to the carbon chain length into short chain CPs $\left(\mathrm{C}_{10}-\mathrm{C}_{13}\right.$, SCCPs $)$, medium chain CPs $\left(\mathrm{C}_{14}-\mathrm{C}_{17}\right.$, MCCPs), and long chain CPs $\left(\mathrm{C}_{18}-\mathrm{C}_{30}, \mathrm{LCCPs}\right)^{2}$, or categorized based on the chlorination degree such as 40$50 \%, 50-60 \%$, and $60-70 \% .^{3}$ SCCPs are particularly of concern due to their higher bioaccumulation potential and greater toxicity to aquatic animals and mammals than the other CP groups. ${ }^{4}$ The presence of SCCPs has been reported in various environmental matrices from different countries and regions such as air, ${ }^{5,6}$ water, ${ }^{7,8}$ sediment, ${ }^{9,10}$ soils, ${ }^{1,12}$ and biota. $^{13-15}$ The Persistent Organic Pollutants (POPs) Review Committee of the Stockholm Convention (SC) has listed SCCPs as a POPs candidate and evaluated SCCPs against the criteria of Annex E in 2008. ${ }^{16}$

CPs production in China began at the end of 1950s and has grown rapidly in recent years. Most of the manufacturing plants are distributed around the central and northeastern parts of China. The distribution and contamination characteristics of SCCPs in the Chinese environment are very scarce although China is the largest CPs producer in the world. ${ }^{17}$ Our recent study found that high concentrations of SCCPs were present in soil samples collected from an e-waste dismantling area in
China. ${ }^{18}$ Another study on the trophic transfer of SCCPs in an aquatic ecosystem near a municipal sewage treatment plant revealed that SCCPs can be bioaccumulated/biomagnified in the aquatic food chain. ${ }^{19}$

Mollusks have long been used to elucidate the distribution of contaminants such as heavy metals, organometallic compounds, and POPs because of their abundance in marine ecosystems and high accumulation capacity of some pollutants. ${ }^{20,21}$ In the Asia-Pacific Mussel Watch Program (APMW), bivalves were used to indicate POPs pollutions in the marine environment, due to their slow elimination of persistent pollutants, unique sessile lifestyle, and that they are water-respiring filter feeders. ${ }^{22}$

As one of the sampling regions of APMW, the Chinese Bohai Sea Rim economic zone shares a quarter of the total gross domestic product in China, while the ecosystem has also been seriously polluted with the rapid economic development. Mollusks collected from this region have previously been used as potential bioindicators/biomonitors of various POPs. ${ }^{23-25}$ In our previous work, we found that Mytilus edulis (Blue mussel, Myt) and Crassostrea talienwhanensis (Oyster, Ost) could be selected as useful bioindicators to evaluate the pollution of organochlorine pesticides (OCPs), polychlorinated

Received: October 28, 2011

Revised: May 15, 2012

Accepted: May 17, 2012

Published: May 17, 2012 


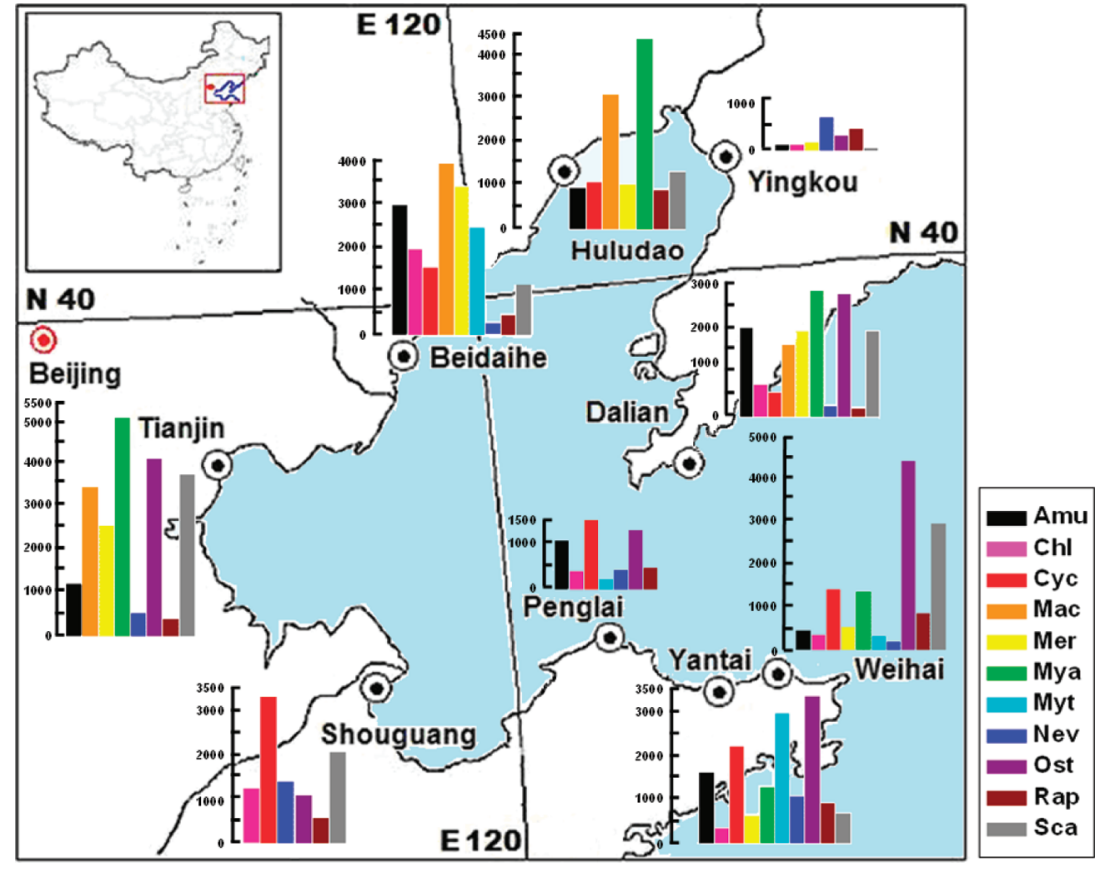

Figure 1. Total SCCP concentrations (ng/g d.w.) in bivalve and gastropod samples collected from the Chinese Bohai Sea.

biphenyls (PCBs), and polybrominated diphenyl ethers (PBDEs) in the Chinese Bohai Sea. ${ }^{26}$

In the present work, we provide a comprehensive investigation on the concentrations of SCCPs in different mollusk species collected from coastal waters of the Chinese Bohai Sea in 2009. The aims are to evaluate concentrations and distribution trends of SCCPs in mollusks and to evaluate whether mollusks are suitable as a biological indicator species of SCCPs in this region. Congener group patterns and possible factors influencing the bioaccumulation of SCCPs in mollusks are also discussed.

\section{MATERIALS AND METHODS}

Sampling. For each sample and sampling site, about 300$500 \mathrm{~g}$ of wet mollusk muscles were composited into one sample. A total of 91 composite mollusk samples were collected from nine coastal cities along the Bohai Sea, including Beidaihe (BDH), Dalian (DL), Huludao (HLD), Penglai (PL), Shouguang (SG), Tianjin (TJ), Weihai (WH), Yantai (YT), and Yingkou (YK) in August, 2009 (Figure 1). Nine of the species were bivalves, including Amusium (Amu), Chlamys Farreri (Chl), Cyclina sinensis (Cyc), Crassostrea talienwhanensis (Oyster, Ost), Mactra veneriformis (Mac), Meretix meretrix (Mer), Mya arenaria (Mya), Mytilus edulis (Blue mussel, Myt), and Scapharca subcrenata (Sca). The other two species were gastropods, Neverita didyma (Nev) and Rapana venosa (Rap).

Sample Pretreatment. Pesticide grade acetone, cyclohexane, dichloromethane (DCM), $n$-hexane ( $n$-Hex), and toluene were purchased from Fisher (Hampton, NH). Silica gel (180-280 mesh) and Florisil (60-100 mesh) were obtained from Merck (Whitehouse Station, NJ). Silica gel was activated at $550{ }^{\circ} \mathrm{C}$ for $12 \mathrm{~h}$, Florisil at $140{ }^{\circ} \mathrm{C}$ overnight, and anhydrous sodium sulfate at $660{ }^{\circ} \mathrm{C}$ for $6 \mathrm{~h}$ before use. Reference SCCPs (chlorine contents of 51.5\%, 55.5\%, and $63.0 \%$ ) and MCCPs (chlorine contents of $42.0 \%, 52.0 \%$, and $57.0 \%$ ) with concentrations of $100 \mathrm{ng} / \mu \mathrm{L}$ in cyclohexane, and $\varepsilon$-hexachlorocyclohexane $(\varepsilon-\mathrm{HCH}$, solution in cyclohexane, 10 $\mathrm{ng} / \mu \mathrm{L}$ ) were purchased from Dr. Ehrenstorfer $\mathrm{GmbH}$ (Augsburg, Germany). ${ }^{13} \mathrm{C}_{10}$-trans-chlordane (100 ng/ $\mu \mathrm{L}$ solution in $n$-nonane, purity $99 \%)$ was purchased from Cambridge Isotope Laboratories (Andover, MA).

An amount of $0.5-1.0 \mathrm{~g}$ of freeze-dried and homogenized mollusk sample was mixed with $15 \mathrm{~g}$ of anhydrous $\mathrm{Na}_{2} \mathrm{SO}_{4}$, spiked with $1 \mathrm{ng}$ of ${ }^{13} \mathrm{C}_{10}$-trans-chlordane, and extracted by dichloromethane and $n$-hexane $(1: 1)$ using a Dionex 350 accelerated solvent extractor $\left(150{ }^{\circ} \mathrm{C}\right.$ and $\left.1500 \mathrm{psi}\right)$. The thermal equilibration time was $10 \mathrm{~min}$, and the static extractions were performed within three cycles $(8 \mathrm{~min} /$ cycle $)$. The cell was purged with gaseous nitrogen for $100 \mathrm{~s}$. After extraction, about $8 \mathrm{~g}$ of acid silica gel ( $44 \%$ concentrated sulfuric acid, w/w) was added to the extract to remove lipid and other interferences and then filtered through approximately $5 \mathrm{~g}$ of anhydrous sodium sulfate. The extract was then cleaned by a multilayered column consisting, from bottom to top, of $3 \mathrm{~g}$ of activated Florisil, $2 \mathrm{~g}$ of activated silica gel, $5 \mathrm{~g}$ of acid silica gel $(30 \%, \mathrm{w} / \mathrm{w})$, and $4 \mathrm{~g}$ of anhydrous sodium sulfate. The detailed cleanup procedures can be found in our previous published work. $^{18}$

Instrumental Analysis. The instrument analysis was performed on a $7000 \mathrm{~A}$ triple quadrupole mass spectrometer combined with a 7890A GC in ECNI mode (Agilent, CA). Samples were injected by a $7683 \mathrm{~B}$ series injector into a DB5MS column (30 m length, $0.25 \mathrm{~mm}$ i.d., $0.25 \mu \mathrm{m}$ film thickness; Agilent, CA). Instrumental parameters and the monitored fragmentation ions of the GC-ECNI-LRMS method have been described in our previous work. ${ }^{12}$ The initial oven temperature was isothermal at $100{ }^{\circ} \mathrm{C}$ and held for $1 \mathrm{~min}$, increased at $30^{\circ} \mathrm{C} / \mathrm{min}$ to $160{ }^{\circ} \mathrm{C}$ for $5 \mathrm{~min}$, then increased to $310{ }^{\circ} \mathrm{C}$ at $30{ }^{\circ} \mathrm{C} / \mathrm{min}$ and held for $22 \mathrm{~min}$. Helium was the carrier gas at a constant flow rate of $2.00 \mathrm{~mL} / \mathrm{min}$, and methane was used as the moderating gas at a constant flow rate of 0.40 $\mathrm{mL} / \mathrm{min}$. The injector temperature was $280{ }^{\circ} \mathrm{C}$. The ion source and transfer line temperatures were 200 and $280{ }^{\circ} \mathrm{C}$, respectively. The target SCCP congener groups included 
Table 1. Sample Information, Lipid Content (\% d.w.), Trophic Level (TL), and SCCP Concentration (ng/g d.w.) of Bivalves and Gastropods Collected from the Chinese Bohai Sea

\begin{tabular}{|c|c|c|c|c|c|c|c|c|c|}
\hline species & class & order & $n$ & lipid content (\% d.w.) & $\mathrm{TL}$ & mean & median & $\min$ & $\max$ \\
\hline Mya & Bivalvia & Myoida & 5 & $11.3 \pm 0.89$ & $2.64 \pm 0.27$ & 3100 & 2990 & 1430 & 5510 \\
\hline Mac & Bivalvia & Veneroida & 6 & $7.93 \pm 0.64$ & $3.16 \pm 0.18$ & 2780 & 2820 & 1410 & 3770 \\
\hline Ost & Bivalvia & Veneroida & 7 & $15.7 \pm 2.22$ & $2.91 \pm 0.38$ & 2640 & 2910 & 302 & 4780 \\
\hline Mer & Bivalvia & Veneroida & 13 & $13.6 \pm 1.80$ & $3.11 \pm 0.40$ & 1830 & 2580 & 174 & 5120 \\
\hline Sca & Bivalvia & Arcoida & 8 & $13.2 \pm 4.54$ & $2.99 \pm 0.66$ & 1710 & 1400 & 64.9 & 4090 \\
\hline Сус & Bivalvia & Veneroida & 7 & $7.51 \pm 1.99$ & $2.91 \pm 0.38$ & 1630 & 1440 & 483 & 3200 \\
\hline Myt & Bivalvia & Mytioida & 5 & $14.1 \pm 3.08$ & $2.88 \pm 0.47$ & 1440 & 1240 & 220 & 3280 \\
\hline $\mathrm{Amu}$ & Bivalvia & Pterioida & 8 & $11.0 \pm 3.05$ & $3.06 \pm 0.19$ & 1230 & 1150 & 135 & 2540 \\
\hline Chl & Bivalvia & Pterioida & 7 & $14.0 \pm 2.55$ & $2.96 \pm 0.16$ & 758 & 640 & 135 & 1660 \\
\hline $\mathrm{Nev}$ & Prosobranchia & Gastropoda & 8 & $6.18 \pm 0.02$ & $3.30 \pm 0.15$ & 610 & 506 & 217 & 1210 \\
\hline Rap & Prosobranchia & Gastropoda & 17 & $6.65 \pm 1.77$ & $3.32 \pm 0.22$ & 584 & 591 & 158 & 1460 \\
\hline
\end{tabular}

chlorine numbers from 5 to 10 , and a total number of 24 congener groups were monitored. The two most abundant isotopes of the $[\mathrm{M}-\mathrm{Cl}]^{-}$ion were selected for the quantitative and qualitative ions.

In order to minimize the possible interferences of MCCPs in environmental samples, the retention time range of each SCCP or MCCP congener group was carefully determined. The integration range of the quantitative ion was set by the comparison of the peak cluster shape between quantitative ion and qualitative ion and must be in the range of the corresponding retention time of the standards. The ratios of the quantitative ion and qualitative ion were calculated based on the chromatographic and mass spectrometric results of SCCP and MCCP standards and then corrected for in the samples. The ratios of each pair of monitored ions were compared between the standards and real samples. If the ratio in the sample fell into the range of the MCCP standard, the end point of the integration range would be modified according to the starting retention time of the corresponding MCCP congener.

Stable Nitrogen Isotope Analysis and Trophic Level Calculations. $\delta^{15} \mathrm{~N}$ was determined in mollusk (dry samples) using a Thermo DELTA V Advantage isotope ratio mass spectrometer interfaced to a Flash EA1112 HT elemental analyzer (Thermo Fisher, Waltham, MA), and atmospheric nitrogen was used as a standard. The delta $(\delta)$ unit is given in parts per thousand according to

$$
\delta^{15} \mathrm{~N}=\left[\left(R_{\text {sample }} / R_{\text {standard }}\right)-1\right] \times 1000 \% \text { o }
$$

where $R$ is the corresponding ratio ${ }^{15} \mathrm{~N} /{ }^{14} \mathrm{~N}$ and the analytical precision was $\pm 0.2 \%$.

Based on the measured nitrogen isotope ratios in mollusks, TLs of mollusks in this study were calculated to indicate the trophic position of the species using the following formula: ${ }^{27}$

$$
\mathrm{TL}=\left(\delta^{15} \mathrm{~N}_{\text {consumer }}-\delta^{15} \mathrm{~N}_{\text {zooplankton }}\right) / 3.8+2
$$

Quality Assurance/Quality Control. All glassware was thoroughly rinsed with dichloromethane and heated at $400{ }^{\circ} \mathrm{C}$ overnight before use. The ASE cell was ultrasonicated twice and rinsed with dichloromethane twice by the ASE instrument at $150{ }^{\circ} \mathrm{C}$ prior to use. Method blank samples were included in each batch of eight samples to monitor potential contamination. In general, levels of SCCPs in blanks were close to or below the limit of detection (LOD), which was estimated at 0.1 ng. The recovery of ${ }^{13} \mathrm{C}_{10}$-trans-chlordane was between $88 \%$ and $101 \%$.

\section{RESULTS AND DISCUSSION}

Comparisons among Sampling Sites. Table 1 summarizes the concentrations of total SCCPs ( $\sum$ SCCPs) based on dry weight (d.w.) in mollusks. The concentration of $\sum$ SCCPs in the mollusks ranged from 64.9 (Sca, YK) to $5510 \mathrm{ng} / \mathrm{g}$ (Mya, $\mathrm{TJ}$ ) with an average of $1410 \mathrm{ng} / \mathrm{g}$. The average converted wet weight concentration (201 ng/g) was lower than $1205 \mathrm{ng} / \mathrm{g}$ (wet weight) found in zebra mussels reported by Tomy et al. Figure 1 shows SCCP concentrations (ng/g d.w.) in mollusks from different sampling sites. In Tianjin (TJ), the largest city in the Bohai Sea region and an important chemical base in China, the collected mollusks showed the highest $\sum$ SCCPs, with an average value of $2830 \mathrm{ng} / \mathrm{g}$ d.w. $\sum$ SCCPs in mollusks from Yingkou (YK) and Penglai (PL) were the lowest with average concentrations of 293 and $708 \mathrm{ng} / \mathrm{g}$ d.w., respectively.

Figure 2 illustrates the carbon chain length and chlorine number patterns in mollusk samples from the sampling locations. Overall, contributions from $\mathrm{C}_{10}$ and $\mathrm{C}_{11}$ congeners were relatively high in mollusks of the Chinese Bohai Sea, which accounted for $29.7 \%$ and $34.9 \%$ of $\sum$ SCCPs, respectively. Most congeners were $\mathrm{Cl}_{6}$ and $\mathrm{Cl}_{7}$ substitutents, which accounted for about $43.7 \%$ and $33.5 \%$ of $\sum$ SCCPs, respectively. The SCCP congener group abundance patterns in mollusk samples were consistent with those reported for sediments in the same region. ${ }^{28}$

Figure 2 also illustrates the percent relative contributions of SCCP homologues in regards to individual carbon chain groups and chlorine number groups. Samples from YK and PL exhibited the lowest concentrations of $\sum$ SCCPs, and the percent relative contributions of $\mathrm{C}_{13}$ congeners were significantly lower than those in other locations, which might be due to the relatively lower amount of the usage of MCCPs commercial products in these sampling areas. ${ }^{29}$

The detection frequency (Supporting Information, Table SI1) of all congeners with $6-8$ chlorine atoms $\left(\mathrm{C}_{x} \mathrm{Cl}_{6-8} ; x=10-\right.$ 13) were above $70 \%$ in the samples, while the others $\left(\mathrm{C}_{x} \mathrm{Cl}_{5,9,10}\right)$ were below 50\%. $\mathrm{C}_{10} \mathrm{H}_{16} \mathrm{Cl}_{6}, \mathrm{C}_{11} \mathrm{H}_{17} \mathrm{Cl}_{7}$, and $\mathrm{C}_{11} \mathrm{H}_{18} \mathrm{Cl}_{6}$ could be detected in over $90 \%$ of the samples and accounted for $14.5 \%, 13.5 \%$, and $10.4 \%$ of $\sum$ SCCPs, respectively. Among all samples, $\mathrm{C}_{13} \mathrm{H}_{23} \mathrm{Cl}_{5}$ was only found in one sample from $\mathrm{TJ}$ (Mac), and $\mathrm{C}_{12} \mathrm{H}_{21} \mathrm{Cl}_{5}$ was found only in Ost from PL and Sca from WH.

Comparisons among Mollusks Species. It was interesting to find that bivalves generally had higher concentrations of SCCPs than gastropods in most of the sampling sites although they are positioned lower in the food chain than gastropods. The average concentrations of SCCPs in Mya was $3100 \mathrm{ng} / \mathrm{g}$ 

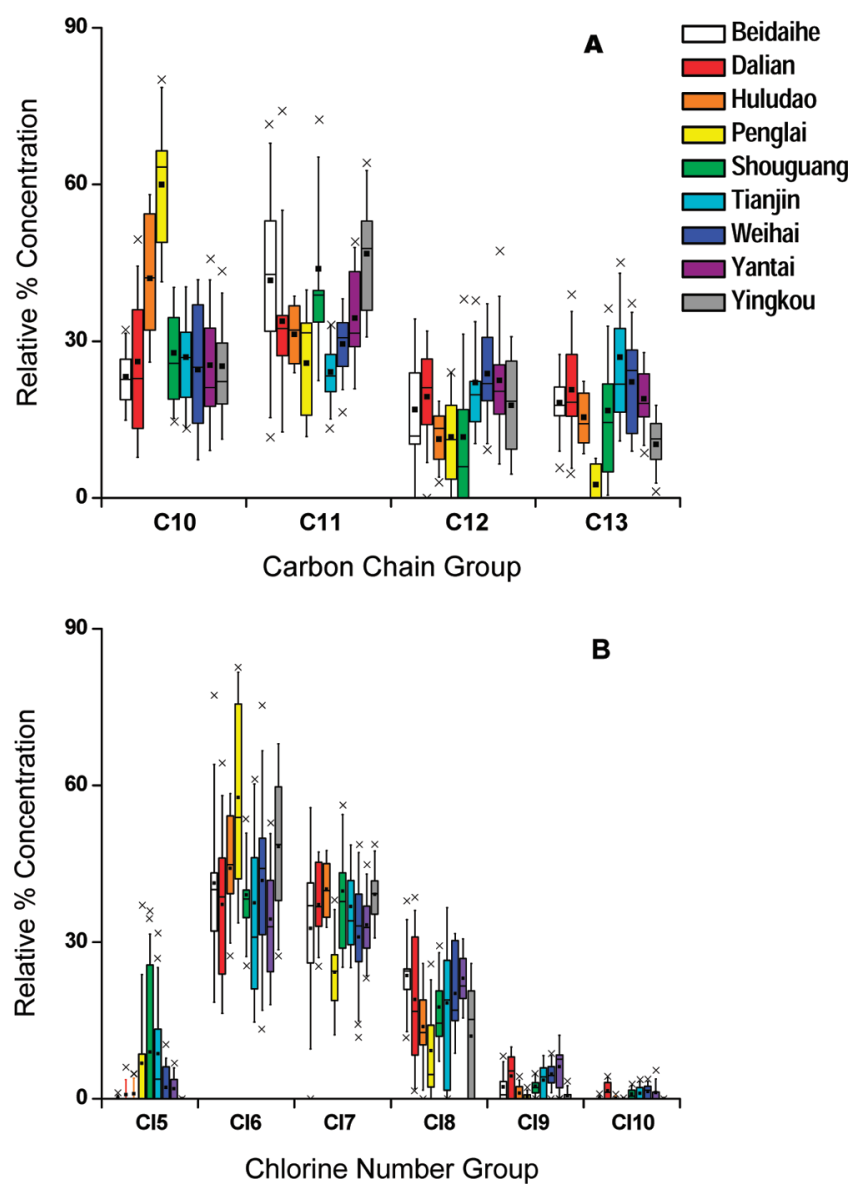

Figure 2. Box-and-whisker plots of percent relative contributions of SCCP homologues of (A) individual carbon chain groups and (B) and chlorine number groups in mollusks samples from different locations around the Bohai Sea. The horizontal black line in the box represents the median value, and the lower and upper edges of the box mark the 25th and 75th percentiles. The whiskers extending from the box show the highest and lowest values that are nonoutliers. " $x$ " represents singular values, which are beyond the 150th percentile of the difference between 25 th and 75 th percentiles.

d.w., and three sampling sites (DL, HLD, and TJ) were found to have much higher levels than other species (Figure 1 and Table 1). Besides, Mac and Ost also showed high levels of $\sum$ SCCPs, with average concentrations of 2780 and $2640 \mathrm{ng} / \mathrm{g}$ d.w., respectively. The bivalve $\mathrm{Chl}$ and two gastropod species Rap and Nev had the lowest concentrations with average concentrations of 758, 610, and $584 \mathrm{ng} / \mathrm{g}$ d.w., respectively. Generally, concentrations of SCCPs (d.w.) in selected mollusk samples were in the following taxonomic order: Myoida > Veneroida $>$ Arcoida $>$ Mytioida $>$ Pterioida $>$ Gastropoda.

The SCCP congener group patterns in gastropods and bivalves show different characteristics (Figure 3 ). The percentage of $\mathrm{C}_{13}$ congeners decreased significantly from Mya to Rap with decreasing concentrations of $\sum$ SCCPs (Supporting Information, Figure SI-1A). The average percentages of $\mathrm{C}_{12}(18.2 \%)$ and $\mathrm{C}_{13}$ congeners $(18.6 \%)$ in bivalves were higher than those in gastropods $(16.7 \%$ and $15.4 \%$, respectively). The proportions of lower chlorinated congener groups $\left(\mathrm{Cl}_{5,6}\right)$ decreased from Rap to Mya, while for SCCPs with more than seven chlorine atoms, the opposite trend was found (Supporting Information, Figure SI-1B). The average percentages of $\mathrm{Cl}_{5,6}$ homologues in gastropods Rap and Nev
(Figure 3A, B) were higher than those in bivalve samples, whereas for the higher chlorinated congener groups $\mathrm{Cl}_{7,8}$, the average percentages in gastropods were lower than those in bivalves.

An exception among the bivalve samples was Mya (Figure $3 \mathrm{D})$, where $\mathrm{Cl}_{8}$ congeners were the second most abundant chlorine homologue and the percentage exceeded that of the $\mathrm{Cl}_{6}$ group. The taxonomic order Pterioida, including Amu and Chl, had the second lowest levels of $\sum$ SCCPs and showed different SCCPs homologue patterns compared to other bivalve species and gastropods. No congeners with $\mathrm{Cl}_{5,10}$ were detected in Chl (Figure 3C) and were only detected in a few samples of Amu. $\mathrm{C}_{10} \mathrm{H}_{16} \mathrm{Cl}_{6}$ and $\mathrm{C}_{11} \mathrm{H}_{18} \mathrm{Cl}_{6}$ were the main congener groups in $\mathrm{Amu}$ and $\mathrm{Chl}$, which was similar to Rap and Nev. The characteristic SCCP patterns in these species might indicate their different bioaccumulation and elimination potential of SCCPs.

Relevance of Lipid Content. SCCPs are hydrophobic and tend to be accumulated in lipids. Previous works reported that the octanol-water partition coefficient $\left(\log K_{\text {ow }}\right)$ values of a series of commercial and synthesized SCCPs ranged from 4.01 to $8.67,{ }^{30}$ which indicated high lipid solubility and strong bioaccumulation potential in aquatic organisms. In this work, the lipid content of selected mollusks was in the ranges 1.98$18.8 \%$ (d.w.) or $0.53-2.96 \%$ on a wet weight basis. The highest lipid contents were found in Ost $(15.7 \pm 2.22 \%$ d.w. $)$. The two gastropods, Nev and Rap, that had the lowest levels of $\sum$ SCCPs, also contained the lowest lipid content.

Significant linear relationship was found between the lipid content of mollusks and $\sum$ SCCPs $(P<0.05$, Figure $4 A)$. Lipid normalized concentrations of SCCPs in mollusks were linearrelated to the length of the carbon chain $(R=0.41, P<0.05)$, and a significant but relatively weak parabolic correlation was found between the concentrations and the number of chlorines ( $R=0.55, P<0.05)$. In order to evaluate the bioaccumulation of an individual congener in the marine species, we also analyzed the relationships among the concentrations of individual congeners (d.w.) and lipid contents. In general, positive linear relationships were found between the concentrations of an individual SCCP congener and the lipid content, although the correlations of some congeners (Supporting Information, Table SI-2) were not significant.

The slope of the linear regression can be considered as an indication of the bioaccumulation capacity of SCCP congener groups in mollusks. A steeper slope implies that the corresponding congener is more influenced by the lipid content. Based on the results of the regression analysis shown in Table SI-2 of the Supporting Information, the relationships among the slopes and carbon and chlorine numbers were analyzed. A relatively weak but significant positive linear correlation was found between carbon number and the concentration-lipid slope (Figure 4B), which indicated that longer carbon chain congeners could be more affected by the lipid contents of the species. $\log K_{\mathrm{ow}}$ is the principal factor describing the liposolubility of POPs. The trend in Figure 4B is consistent with the experimental results obtained by Hilger et al. where the $\log K_{\mathrm{ow}}$ values of SCCPs are linear dependent on the alkane chain length (at chlorination degrees of $45-70 \%)^{30}$ and also similar to the work by Drouillard et al., which reported decreasing aquatic solubility of SCCPs when the carbon numbers increased from 10 to $12 .^{31}$

The parabola was open downward for the regression between chlorine number and concentration-lipid slopes of the 

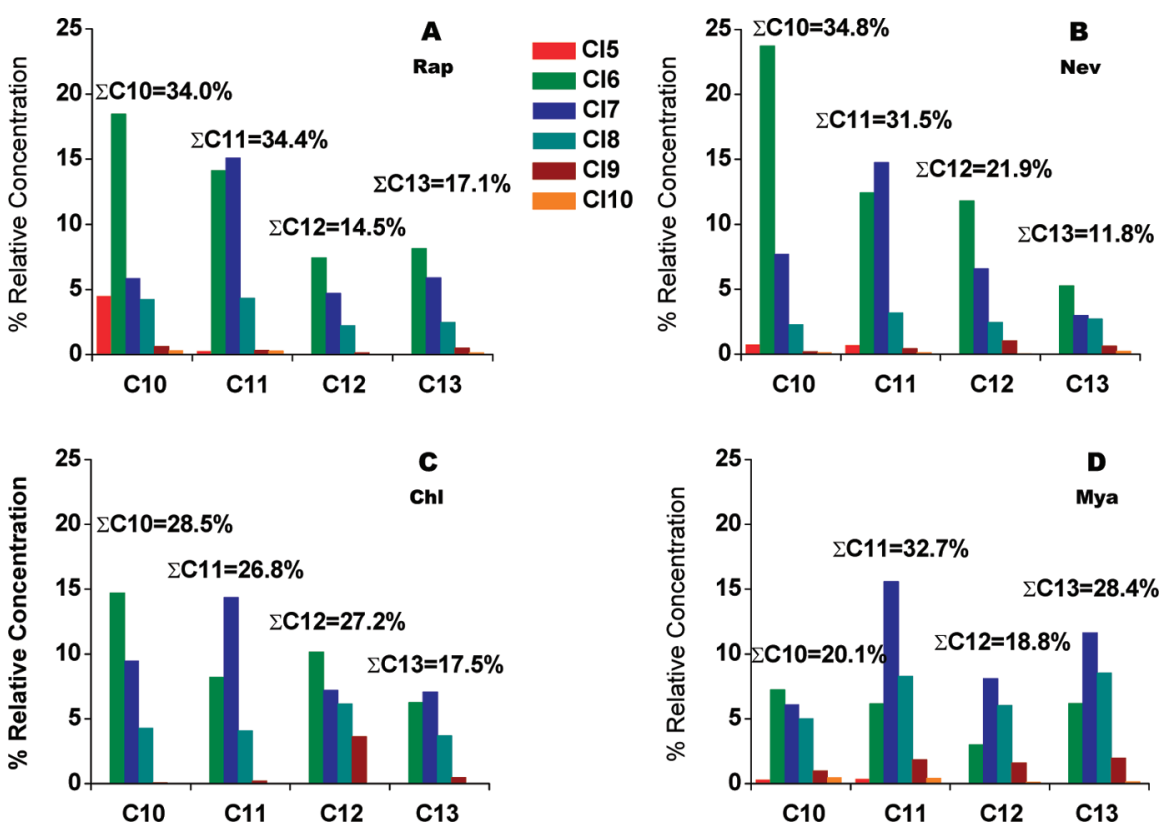

Figure 3. Average percentage of SCCP congener pattern in mollusk samples (A) Rap, (B) Nev, (C) Chl, and (D) Mya.
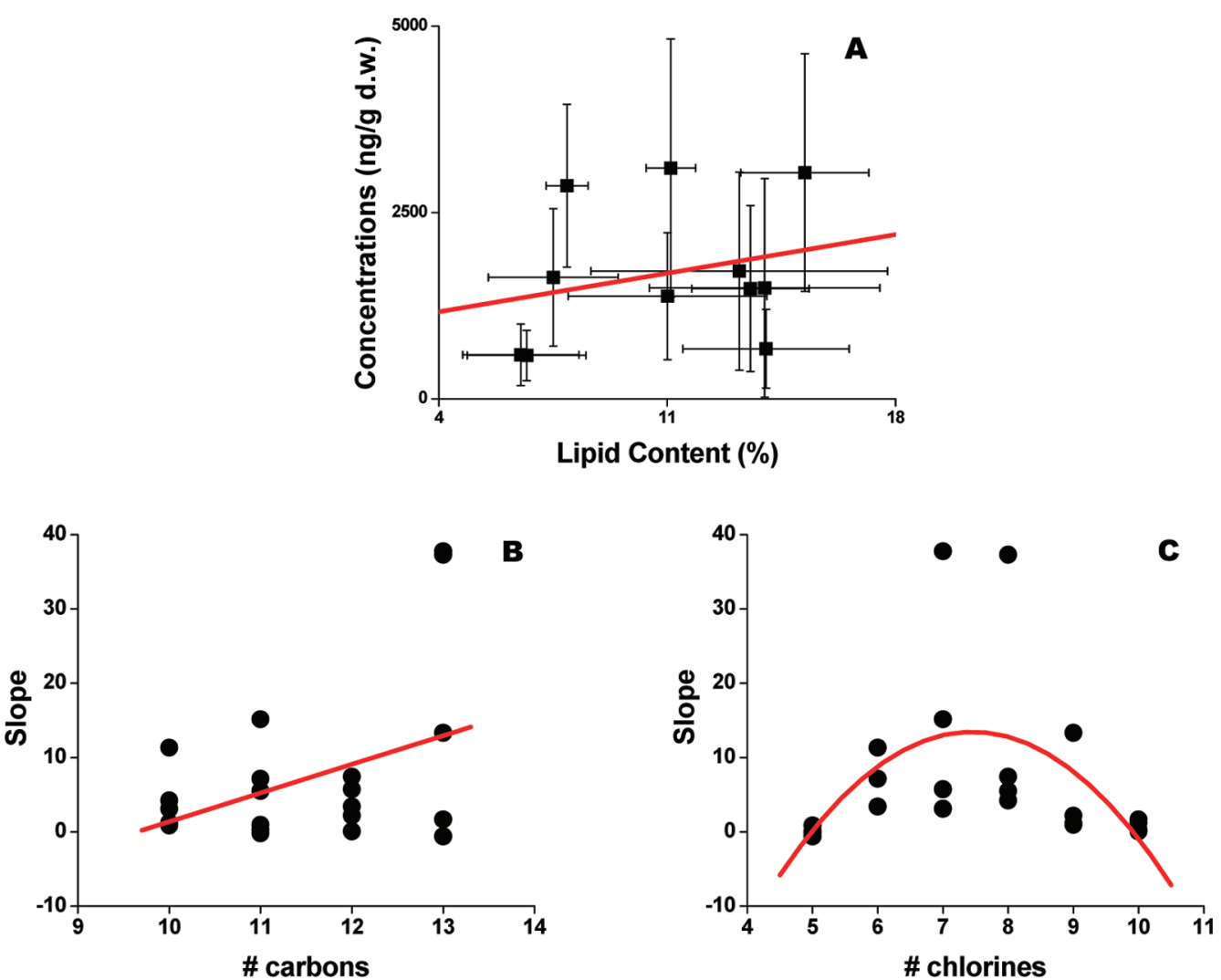

Figure 4. Relationships between dry-weight-based $\sum$ SCCPs with lipid content (A: $\sum$ SCCPs ng/g d.w. $=383+96.5 \times$ lipid content, $R=0.31, P<$

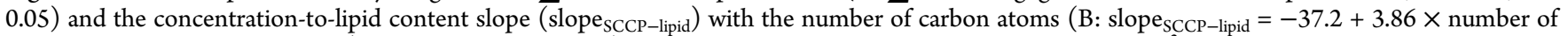
carbon atoms, $R=0.41, P<0.05$ ) and chlorine numbers (C: slope ${ }_{\mathrm{SCCP}-\text { lipid }}=-110+33.0 \times \# \mathrm{Cl}-2.22 \times \# \mathrm{Cl}^{2}$, \#Cl: chlorine numbers, $R=0.55, P$

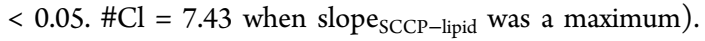

individual congener (Figure $4 \mathrm{C}, R=0.55, P<0.05$ ). The vertex can be found at $\# \mathrm{Cl}=7.43$, which could imply that bioaccumulation of congeners with $\mathrm{Cl}_{7,8}$ in mollusks are most influenced by lipid contents. The chlorination degree of SCCPs was in the range from $49.8 \%\left(\mathrm{C}_{13} \mathrm{H}_{23} \mathrm{Cl}_{5}\right)$ to $72.9 \%$ $\left(\mathrm{C}_{10} \mathrm{H}_{12} \mathrm{Cl}_{10}\right)$. If taking chlorination degree $(\mathrm{Cl} \%)$ of the congener groups as the $x$ axis, similar trends were also found with significant correlations (Supporting Information, Figure SI-2, $R=0.52, P<0.05)$. The second-order polynomial correlation was also found in the study by Hilger et al. ${ }^{30}$ The main difference was that the vertex value in our work was found at $\mathrm{Cl} \%=60.6 \%$ whereas the calculated vertex was at about $50 \%$ 

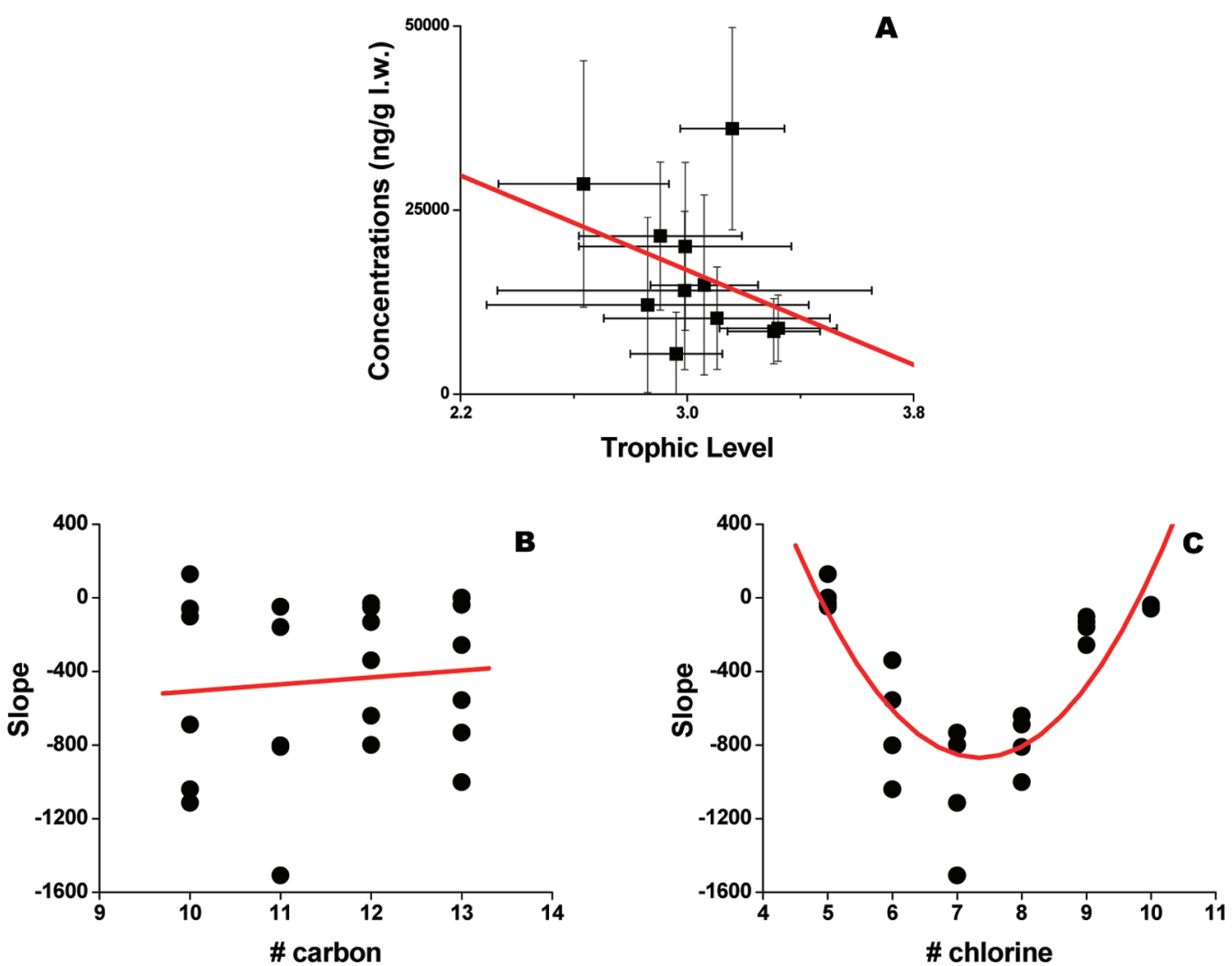

Figure 5. Relationships between lipid-weight-based $\sum$ SCCPs with TL (A: $\sum$ SCCPs ng/g l.w. $=46000-10700 \times$ TL, $\left.R=-0.34, P<0.05\right)$ and the concentration-to-TL slope ( slope $_{\mathrm{SCCP}-\mathrm{TL}}$ ) with the number of carbon atoms $\left(\mathrm{B}\right.$ : slope $\mathrm{SCCP}_{\mathrm{TL}}=-885+37.7 \times$ number of carbon atoms, $R=$ $0.10, P=0.66)$ and chlorine numbers $\left(\mathrm{C}\right.$ : slope $\mathrm{SCCP}-\mathrm{TL}=6810-2090 \times \# \mathrm{Cl}+142.21 \times \# \mathrm{Cl}^{2}$, \#Cl: chlorine numbers, $R=0.83, P<0.05$. \#Cl=7.35 when slope SCCP-TL $_{\text {was a maximum). }}$.

in their report. If assuming lipid content is the only factor dominating the accumulation of SCCPs in mollusks, the trend of concentration-lipid slope should be similar as with the log $K_{\text {ow }}$ of the congener groups, which would be increasing with the increase of $\mathrm{Cl} \%$. However, the results deduced in this work deviated from the theoretical trend.

A parabolic relationship between $\log K_{\mathrm{ow}}$ and the total number of carbon and chlorine atoms $\left(N_{\text {tot }}\right)$ of SCCPs has been found by Sijm and Sinnige. ${ }^{32}$ They pointed out that log $K_{\text {ow }}$ increased with the $N_{\text {tot }}$ and began to decrease when $N_{\text {tot }}$ exceeded 23.1 (in this study, the maximum $N_{\text {tot }}$ is 23 for $\mathrm{C}_{13} \mathrm{H}_{18} \mathrm{Cl}_{10}$ ). However, the maximum slope was at $N_{\text {tot }}=20.3$ in the parabolic curve of concentration-lipid slope and $N_{\text {tot }}$ (Supporting Information, Figure SI-4, the parabolic relationship were not significant). The shift between the maximum value of $N_{\text {tot }}$ and the deviation of the relationship between $\log K_{\text {ow }}$ and $\mathrm{Cl} \%$ in this work from the references studies indicated that some other factors could affect the bioaccumulation of SCCPs.

It is notable that, in most cases, the $\sum$ SCCPs of Mya and Mac were generally higher than other species, although the average lipid contents were only $11.3 \pm 0.89 \%$ d.w. and $7.93 \pm$ $0.64 \%$ d.w., respectively. On the contrary, the $\sum$ SCCPs in Chl samples was as low as gastropod samples, and no $\mathrm{Cl}_{5}$ or $\mathrm{Cl}_{10}$ congeners were detected in spite of the high lipid content (14.0 $\pm 2.55 \%$ d.w.).

Relevance of Trophic Level (TL). Nitrogen isotope ratios can indicate the trophic position of a marine species and have been widely used to study the bioaccumulation/biomagnification of organic contaminants through the food chain. ${ }^{27,33}$ Mollusks are water-respiring filter feeders and generally considered at the second lowest level in the marine food web. The main sources of contaminants are via food intake and water. The TL for all species was in the range 2.12-4.00 (Table 1 ), which is consistent with previous work. ${ }^{34}$ Among the 11 species, the predatory gastropods $\mathrm{Nev}$ and Rap were at a higher TL than other species (Nev: $3.30 \pm 0.15$; and Rap: $3.32 \pm$ 0.22 ), although $\sum$ SCCPs in Nev and Rap were lower than in bivalves. Mya had the highest average concentrations of SCCPs in spite of the lowest TL $(2.64 \pm 0.27)$.

Investigation on the correlations between the lipidnormalized $\sum$ SCCPs and TL showed a significant negative linear relationship between $\sum$ SCCPs and TL $(p<0.05$, Figure $5 A$ ), which was similar to the trends of higher chlorinated polychlorinated dibenzo- $p$-dioxins and polychlorinated dibenzofurans (PCDD/Fs) and PCBs in food chains of the Chinese Bohai Sea. ${ }^{26,35}$ No significant linear relationship was found between carbon number and the concentration-TL slope although the trend was slightly increasing (Table SI-2 of the Supporting Information and Figure 5B). The correlation between chlorine number and the concentration (l.w.)-to-TL slopes of an individual congener was parabolic $(R=0.83, P<$ 0.05 ). If the $x$ axis was changed from the number of chlorine to $\mathrm{Cl} \%$ (Supporting Information, Figure SI-3), the parabolic correlation was significant as well $(R=0.67, P<0.05)$, and the vertex was found at $\mathrm{Cl} \%=61.5 \%$.

The concentration (l.w.)-to-TL slope first slightly decreased and then increased with the increase of $N_{\text {tot }}$ (Supporting Information, Figure SI-5). If this trend was described as parabolic, in spite that the relationship was not significant $(R=$ 
$0.41, P=0.16)$, the vertex would be at $N_{\text {tot }}=18.4$, which was lower than that in lipid content $\left(N_{\text {tot }}=20.3\right)$.

Trophic magnification factors (TMFs) were also calculated as the following equations: $\log$ concentration lipid weight $=b \times \mathrm{TL}$ + constant; TMF $=10^{b} .{ }^{19}$ The mean TMF value of major congener groups $\left(\mathrm{C}_{10-13} \mathrm{Cl}_{6-8}\right)$ was 0.238 (Supporting Information, Table SI-3), and TMF for $\sum$ SCCPs was 0.396 (Supporting Information, Figure SI-6), which indicated no trophic magnification of SCCPs in mollusks in the Chinese Bohai Sea.

Similar negative relationships between concentrations and TL were previously also found for other persistent semivolatile compounds such as PCBs, HCHs, PBDEs, and DDTs in mollusks in this region. ${ }^{26}$ However, biomagnification of SCCPs has also been observed in some aquatic food webs, such as plankton-Diporeia-Mysis-alewife-rainbow smelt-sculpinlake trout $^{36}$ and catfish-carp-turtle-tilapia aquatic food chain. ${ }^{19}$ The different biomagnification behaviors of SCCPs in different areas and food webs indicate the complex interplay of physical-chemical and biological processes on the bioaccumulation/biomagnification properties of SCCPs in organisms, such as depuration rate, growth dilution, respiratory elimination, and more.

Although not collected in all sampling sites, the bivalve Mya showed the highest average concentration of $\sum$ SCCPs despite belonging to the lowest trophic level in this study. Mya are abundant in many aquatic and marine ecosystems, including Bering Strait, the west coast of North America, the northern coast of Japan and Korea, and China's Yellow Sea and Bohai Sea. Our previous work found that Mya has a high ability to accumulate organotin compounds, in particular tributyltin (TBT), and could be used as bioindicators to monitor the pollution of organotin compounds in marine system. ${ }^{37}$ Besides Mya, Ost also showed higher concentrations of $\sum$ SCCPs than other species. In another investigation, we also found that Ost could be used as a potential bioindicator for pollutions of OCPs, PCBs, and PBDEs in this study region. These two bivalve species therefore have the prospect of being potential bioindicators of SCCPs contamination or POPs in general.

\section{ASSOCIATED CONTENT}

\section{S Supporting Information}

Tables showing the detection frequency of individual SCCP congeners in each species collected from the Bohai Sea, the slopes from correlation of individual SCCP congener groups with lipid content and the trophic level and their $\mathrm{p}$ values, and the trophic magnification factors of major SCCP congener groups, and figures of the average percentage of SCCP homologues of individual carbon chain groups and chlorine groups, relationship between the concentration-to-lipid content slope and the chlorination degree, relationship between the lipid-weight-based $\sum$ SCCPs to TL slope and the chlorination degree, relationship between the concentration-to-lipid content slope and the total number of carbon and chlorine atoms, relationship between the lipid-weight-based $\sum$ SCCPs to TL slope and the total number of carbon and chlorine atoms, and the relationship between the logarithm of lipid-weight-based $\Sigma$ SCCPs and trophic level. This material is available free of charge via the Internet at http://pubs.acs.org.

\section{AUTHOR INFORMATION}

\section{Corresponding Author}

*Phone: 8610-6284-9334; fax: 8610-6284-9339; e-mail: ywwang@rcees.ac.cn.

\section{Notes}

The authors declare no competing financial interest.

\section{ACKNOWLEDGMENTS}

This work was jointly supported by the National Natural Science Foundation (21077114 and 20890111), the National Basic Research Program of China (2009CB421605), the National High Technology Research and Development Program of China (2010AA065102), and Chinese Academy of Sciences (KZCX2-YW-QN409).

\section{REFERENCES}

(1) Fiedler, H. Short-chain chlorinated paraffins: production, use and international regulations. In Chlorinated Paraffins. The Handbook of Environmental Chemistry; de Boer, J., Ed.; Springer-Verlag: Berlin, Germany, 2010; pp 1-40.

(2) Tomy, G. T.; Stern, G. A.; Muir, D. C. G.; Fisk, A. T.; Cymbalisty, C. D.; Westmore, J. B. Quantifying $\mathrm{C}_{10}-\mathrm{C}_{13}$ polychloroalkanes in environmental samples by high-resolution gas chromatography/electron capture negative ion high-resolution mass spectrometry. Anal. Chem. 1997, 69, 2762-2771.

(3) Pribylova, P.; Klanova, J.; Holoubek, I. Screening of short- and medium-chain chlorinated paraffins in selected riverine sediments and sludge from the Czech Republic. Environ. Pollut. 2006, 144, 248-254.

(4) Muir, D. C.; Stern, G. A.; Tomy, G. T. Chlorinated paraffins. The handbook of environmental chemistry. In New Types of Persistent Halogenated Compounds; Paasivirta, J., Ed.; Springer-Verlag: Berlin, Germany, 2000; Ch 8, p 3.

(5) Barber, J. L.; Sweet,am, A. J.; Thomas, G. O.; Braekevelt, E.; Stern, G. A.; Jones, K. C. Spatial and temporal variability in air concentrations of short-chain (C10-C13) and medium-chain (C14C17) chlorinated n-alkanes measured in the U.K. atmosphere. Environ. Sci. Technol. 2005, 39, 4407-4415.

(6) Friden, U. E.; McLachlan, M. S.; Berger, U. Chlorinated paraffins in indoor air and dust: Concentrations, congener patterns, and human exposure. Environ. Int. 2011, 37, 1169-1174.

(7) Moore, S.; Vromet, L.; Rondeau, B. Comparison of metastable atom bombardment and electron capture negative ionization for the analysis of polychloroalkanes. Chemosphere. 2004, 54, 453-459.

(8) Iino, F.; Takasuga, T.; Senthilkumar, K.; Nakamura, N.; Nakanishi, J. Risk assessment of short-chain chlorinated paraffins in Japan based on the first market basket study and species sensitivity distributions. Environ. Sci. Technol. 2005, 39, 859-866.

(9) Castells, P.; Parera, J.; Santos, F. J.; Galceran, M. T. Occurrence of polychlorinated naphthalenes, polychlorinated biphenyls and shortchain chlorinated paraffins in marine sediments from Barcelona (Spain). Chemosphere. 2008, 70, 1552-1562.

(10) Iozza, S.; Muller, C.; Schmid, P.; Bogdal, C.; Oehme, M. Historical profiles of chlorinated paraffins and polychlorinated biphenyls in a dated sediment core from Lake Thun (Switzerland). Environ. Sci. Technol. 2008, 42, 1045-1050.

(11) Nicholls, C. R.; Allchin, C. R.; Law, R. J. Levels of short and medium chain length polychlorinated $\mathrm{n}$-alkanes in environmental samples from selected industrial areas in England and Wales. Environ. Pollut. 2001, 114, 415-430.

(12) Zeng, L. X.; Wang, T.; Han, W.; Yuan, B.; Liu, Q.; Wang, Y. W.; Jiang, G. B. Spatial and vertical distribution of short chain chlorinated paraffins in soils from wastewater irrigated farmlands. Environ. Sci. Technol. 2011, 45, 2100-2106.

(13) Bennie, D. T.; Sullivan, C. A.; Maguire, R. J. Occurrence of chlorinated paraffins in beluga whales (Delphinapterusleucas) from the St. Lawrence River and rainbow trout (Oncorhynchusmykiss) and carp 
(Cyprinuscarpio) from Lake Ontario. Water Qual. Res. J. Can. 2000, 35, 263-281.

(14) Tomy, G.; Muir, D.; Stern, G.; Westmore, J. B. Levels of C10C13 polychloro-n-alkanes in marine mammals from the Arctic and the St. Lawrence River estuary. Environ. Sci. Technol. 2000, 34, 16151619.

(15) Iozza, S.; Schmid, P.; Oehme, M.; Bassan, R.; Belis, C.; Jakobi, G.; Kirchner, M.; Schramm, K. W.; Krauchi, N.; Moche, W.; Offenthaler, I.; Weiss, P.; Simoncic, P.; Knoth, W. Altitude profiles of total chlorinated paraffins in humus and spruce needles from the Alps (MONARPOP). Environ. Pollut. 2009, 157, 3225-3231.

(16) Wang, Y. W.; Fu, J. J.; Jiang, G. B. The research of environmental pollutions and toxic effect of short chain chlorinated paraffins. Environ. Chem. (Chin.) 2009, 28, 1-9.

(17) Tang, E. T.; Yao, L. Q. Industry status of chlorinated paraffin and its development trends. Chin. Chlor-Alkali (Chin.) 2005, 2, 1-3.

(18) Yuan, B.; Wang, Y. W.; Fu, J. J.; Zhang, Q. H.; Jiang, G. B. An analytical method for chlorinated paraffins and their determination in soil samples. Chin. Sci. Bull. 2010, 55, 2395-2401.

(19) Zeng, L. X.; Wang, T.; Wang, P.; Liu, Q.; Han, S. L.; Yuan, B.; Zhu, N. L.; Wang, Y. W.; Jiang, G. B. Distribution and trophic transfer of short-chain chlorinated paraffins in an aquatic ecosystem receiving effluents from a sewage treatment plant. Environ. Sci. Technol. 2011, $45,5529-5535$.

(20) Tanabe, S. International mussel watch in Asia-Pacific. Mar. Pollut. Bull. 1994, 28, 518.

(21) Tanabe, S.; Prudente, M. S.; Kan-atirelap, S.; Subramanian, A. Mussel watch: marine pollution monitoring of butyltins and organochlorines in coastal waters of Thailand, Philippines and India. Ocean Coastal Manage. 2000, 43, 819-839.

(22) Monirith, I.; Ueno, D.; Takahashi, S.; Nakata, H.; Sudaryanto, A.; Subramanian, A.; Karuppiah, S.; Ismail, A.; Muchtar, M.; Zheng, J.; Richardson, B. J.; Prudente, M.; Hue, N. D.; Tana, T. S.; Tkalin, A. V.; Tanabe, S. Asia-Pacific mussel watch: monitoring contamination of persistent organochlorine compounds in coastal waters of Asian countries. Mar. Pollut. Bull. 2003, 46, 281-300.

(23) Zhao, X.; Zheng, M.; Liang, L.; Zhang, Q.; Jiang, G. Assessment of PCBs and PCDD/Fs along the Chinese Bohai Sea coastline using mollusks as bioindicators. Arch. Environ. Contam. Toxicol. 2005, 49, $178-185$.

(24) Pan, Y. Y.; Shi, Y. L.; Wang, Y. W.; Cai, Y. Q.; Jiang, G. B. Investigation of perfluorinated compounds (PFCs) in mollusks from coastal waters in the Bohai Sea of China. J. Environ. Monit. 2010, 12, 508-513.

(25) Yang, R. Q.; Yao, Z. W.; Jiang, G. B.; Zhou, Q. F.; Liu, J. Y. $\mathrm{HCH}$ and DDT residues in mollusks from Chinese Bohai coastal sites. Mar. Pollut. Bull. 2004, 48, 795-805.

(26) Wang, Y. W.; Wang, T.; Li, A.; Fu, J. J.; Wang, P.; Zhang, Q. H.; Jiang, G. B. Selection of bioindicators of polybrominated diphenyl ethers, polychlorinated biphenyls, and organochlorine pesticides in mollusks in the Chinese Bohai Sea. Environ. Sci. Technol. 2008, 42, $7159-7165$.

(27) Fisk, A. T.; Hoboson, K. A.; Norstrom, R. J. Influence of chemical and biological factors on trophic transfer of persistent organic pollutants in the northwater Polynya marine food web. Environ. Sci. Technol. 2001, 35, 5732-738.

(28) Gao, Y.; Wang, C.; Zhang, H. J.; Zuo, L. L.; Tian, Y. Z.; Chen, J. P. Analysis of short-chain chlorinated paraffins in sediment samples from the mouth of the Daliao River by HRGC/ECNI-LRMS. Environ. Sci. (Chin.) 2010, 31, 1904-1908.

(29) Marvin, C. H.; Painter, S.; Tomy, G. T.; Stern, G. A.; Braekevelt, E.; Muir, D. C. G. Spatial and temporal trends in short-chain chlorinated paraffins in Lake Ontario sediments. Environ. Sci. Technol. 2003, 37, 4561-4568.

(30) Hilger, B.; Fromme, H.; Volkel, W.; Coelhan, M. Effects of chain length, chlorination degree, and structure on the octanol-water partition coefficients of polychlorinated n-alkanes. Environ. Sci. Technol. 2011, 45, 2842-2849.
(31) Drouillard, K. G.; Hiebert, T.; Tran, P.; Tomy, G. T.; Muir, D. C. G.; Friesen, K. J. Estimating the aqueous solubilities of individual chlorinated n-alkanes $(\mathrm{C} 10-12)$ from measurements of chlorinated alkane mixtures. Environ. Toxicol. Chem. 1998, 17, 1261-1267.

(32) Sijm, D. T. H. M.; Sinnige, T. L. Experimental octanol/water partition coefficients of chlorinated paraffins. Chemosphere. 1995, 31, 4427-4435.

(33) Wang, Y. W.; Li, X. M.; Li, A.; Wang, T.; Zhang, Q. H.; Wang, P.; Fu, J. J.; Jiang, G. B. Effect of municipal sewage treatment plant effluent on bioaccumulation of polychlorinated biphenyls and polybrominated diphenyl ethers in the recipient water. Environ. Sci. Technol. 2007, 41, 6026-6032.

(34) Wan, Y.; Hu, J. Y.; An, L. H.; An, W.; Yang, M.; Itoh, M.; Hattori, T.; Tao, S. Determination of trophic relationships within a Bohai Bay food web using stable $\delta 15 \mathrm{~N}$ and $\delta 13 \mathrm{C}$ analysis. Chin. Sci. Bull. 2005, 50, 1021-1025.

(35) Wan, Y.; Hu, J. Y.; Yang, M.; An, L. H.; An, W.; Jin, X. H.; Hattori, T.; Masunaga, S.; Itoh, M. Characterization of trophic transfer for polychlorinated dibenzo-p-dioxins, dibenzofurans, non- and monoortho polychlorinated biphenyls in the marine food web of Bohai Bay, North China. Environ. Sci. Technol. 2005, 39, 2417-2425.

(36) Houde, M.; Muir, D. C. G.; Tomy, G. T.; Whittle, D. M.; Teixeira, C.; Moore, S. Bioaccumulation and trophic magnification of short- and medium-chain chlorinated paraffins in food webs from Lake Ontario and Lake Michigan. Environ. Sci. Technol. 2008, 42, 38933899.

(37) Zhou, Q. F.; Zhang, J. B.; Fu, J. J.; Shi, J. B.; Jiang, G. B. Biomonitoring: an appealing tool for assessment of metal pollution in the aquatic ecosystem. Anal. Chim. Acta 2008, 606, 135-150. 